\title{
Albert Hirschman's Hiding Hand
}

\section{Citation}

Cass R. Sunstein, Albert Hirschman's Hiding Hand (June 10, 2014).

\section{Permanent link}

http://nrs.harvard.edu/urn-3:HUL.InstRepos:16217275

\section{Terms of Use}

This article was downloaded from Harvard University's DASH repository, and is made available under the terms and conditions applicable to Open Access Policy Articles, as set forth at http:// nrs.harvard.edu/urn-3:HUL.InstRepos:dash.current.terms-of-use\#OAP

\section{Share Your Story}

The Harvard community has made this article openly available.

Please share how this access benefits you. Submit a story.

Accessibility 


\title{
Preliminary draft 6/10 \\ All rights reserved
}

\section{Albert Hirschman's Hiding Hand}

\section{Cass R. Sunstein*}

\begin{abstract}
Albert Hirschman argued that planners in underdeveloped nations often benefit from what he called the Hiding Hand, which hides, and thus makes planners unable to anticipate, serious obstacles to development projects. The Hiding Hand turns out to be benevolent, because once the obstacles arise, human creativity, which is also unanticipated, comes to the rescue. Planners would not have authorized the relevant projects if the Hiding Hand had not hidden the obstacles, but fortunately, unanticipated solutions often emerge. This brief essay, the foreword to a new Brookings Press edition of Hirschman's Development Projects Observed, explores the relationship between Hirschman's Hiding Hand and behavioral findings involving unrealistic optimism and the planning fallacy. It also discusses the relationship between behavioral economics and Hirschman's preferred approach, which did not involve identification of testable hypotheses, but instead narrative descriptions of surprising social mechanisms. It also notes that the Benevolent Hiding Hand has an evil sibling, the Malevolent Hiding Hand.
\end{abstract}

Albert Hirschman loved surprises, ironies, and paradoxes. He was delighted by human foibles and even more, he celebrated human creativity. He distrusted large claims and law-like generalizations. He enjoyed serendipity. He insisted that human history provides "stories, intricate and often nonrepeatable," which "look more like tricks history has up its sleeve than like social-scientific regularities, not to speak of laws." A refugee from Berlin during the rise of Nazism, he was keenly interested in "the many might-have-beens of history," including "felicitous and surprising escapes from disaster."

The largest idea in this remarkable book involves the Hiding Hand, which turns out to be a bit of a trick up history's sleeve. It also provides a felicitous escape from disaster. It's a story, and an intricate one, but in Hirschman's view, it is repeatable. Hirschman believes that it tells us a great deal about development, if we are careful to specify the underlying mechanisms.

In Hirschman's account, social planners tend to be unrealistically optimistic, especially in underdeveloped nations. Ironically, that's fortunate, because if they were more realistic, they would not be bold enough to get started in the first place. Planners begin their projects by greatly overestimating some factor or condition that is indispensable to success. According to Hirschman, planners thus tend to blunder in a predictable direction,

\footnotetext{
${ }^{*}$ Robert Walmsley University Professor, Harvard University.
} 
because they neglect "a set of possible and unsuspected threats" to the profitability and even the ultimate existence of their projects. (Modern behavioral scientists would connect Hirschman's claim with both "optimistic bias," by which people show unrealistic optimism, and the "planning fallacy," by which people systemically underestimate the length of time that it takes to complete projects. More on that later.)

Fortunately, the planners' neglect of bad surprises is countered by a much happier surprise, which involves the sheer power of human creativity. Planners do not merely overestimate the likelihood of success; they also underestimate potential responses to failure. Once things begin to go wrong, people discover unexpected ways to set them right. Hence the idea of a Hiding Hand, which "beneficially hides difficulties from us." The oddity is that while planners might never have authorized certain projects if they had had an accurate sense of the obstacles that those projects would encounter, the result of the Hiding Hand is to produce an outcome that is as good as what the planner originally thought—or perhaps even better.

Hirschman offers two explanations for why planners tend to be blind to obstacles and challenges. He calls the first the "pseudo-imitation" technique, which means that planners pretend, or think, "that a project is nothing but a straightforward application of a well-known technique that has been successfully used elsewhere." The devastating problem, of course, is that situations and circumstances are different, so a project that is sold as if it were pure imitation usually has a large component of "indigenous initiative and execution."

The second explanation is the "pseudo-comprehensive-program" technique, by which planners dismiss previous efforts as piecemeal, and portray their own effort as a comprehensive program. With this technique, policymakers give, and are given, the illusion "that the 'experts' have already found all the answers," and all that is needed is faithful implementation. Those who enlist the pseudo-comprehensive-program technique end up underplaying the need for "imagination, insight, and the application of creative energies," thus covering up "the ignorance of the experts about the real cure of the malady they have been summoned to examine."

Sounding a bit like Friedrich Hayek, Hirschman argues that the two explanations turn out to work in concert, with the pseudo-imitation technique making "projects appear less difficulty-ridden than they actually are," and with the pseudo-comprehensive-program technique giving "project planners the illusion than they are in possession of far more insight into the projects' difficulties than is as yet available." Hence the decisionmaker has "crutches" that encourage him to proceed "at a stage when he has not yet acquired enough confidence in his 
problem-solving ability to make a more candid appraisal of a project's prospective difficulties and of the risks he is assuming." (In both developed and developing countries, readers should be able to think of their own favorite examples, past and present.)

That's the bad news. The good news is that far from leading to disaster, the Hiding Hand provides both a spur and a remedy in the form of "a mechanism that makes the risk-averter take risks and in the process turns him into less of a risk-averter." Once risks are taken, human creativity emerges to solve unanticipated problems. The Hiding Hand is certainly not God, but it is pretty benevolent, and it works in mysterious ways. And, in fact, Hirschman invokes "Christianity's oft expressed preference for the repentant sinner," who has learned, "over the righteous man who never strays from the path of virtue." In the same vein, and even more on point, Hirschman invokes Nietzsche's maxim, “That which does not destroy me, makes me stronger."

Hirschman's focus is on development projects in poor nations, but he suggests, with evident delight and perhaps a touch of mischief, that "we may be dealing here with a fairly general phenomenon." That phenomenon has foundations in the claim that "people typically take on and plunge into new tasks because of the erroneously presumed absence of a challenge, because the task looks easier and more manageable than it will turn out to be." But upon finding that the underlying problems "are really more difficult than expected," and having been "stuck with them" because work is already well under way, people attack those problems ferociously—and often turn out to succeed. (Could Hirschman have been referring, in part, to his own life? His escape from Berlin? His extraordinary success in helping thousands of refugees to escape Nazi-occupied France? His academic work? Raising children? Many authors will recognize the Hiding Hand phenomenon in their own lives.)

Hirschman believed that notwithstanding its universality, the Hiding Hand is especially valuable in underdeveloped nations, "where confidence in creativity is lacking." In such nations, planners will be particularly reluctant to embark on projects that have a lot of unknowns, because their humility and caution will make them unwilling to proceed. Their reluctance will be overcome only if they act on the basis of (misplaced, even blind) confidence that obstacles will not arise - and when they do, planners will be surprised by their power to surmount them.

I have mentioned the behavioral findings of unrealistic optimism and the planning fallacy. In recent decades, behavioral scientists have found that most people are more optimistic than reality warrants (hence the 
idea of an "optimistic bias"), believing both that they are less likely to face hardship than other people, and that their personal vulnerability to risk is less than the statistical reality for people in general. People also tend to think that they will be able to complete tasks more quickly than they actually end up doing (hence the idea of a "planning fallacy"). These findings have obvious connections to the idea of the Hiding Hand. Blindness to obstacles can be seen as a form of optimistic bias, linked with the empirical finding that people update their beliefs readily when they hear good news, but have a kind of blindness to bad news. Blindness to obstacles is also a mechanism behind the planning fallacy, though Hirschman is of course concerned with a more general problem than undue optimism about how long it will take to complete projects.

Hirschman would probably have found these behavioral findings, and many others in behavioral science, to represent a significant advance over standard economic thinking, which emphasizes the decisions of rational actors. Alert to human foibles and to the complexity of human motivations, he can easily be seen as an early behavioral economist, and this book can plausibly be counted as a work in behavioral economics. But Hirschman was one of a kind, and he defies classification. With his keen narrative sense, and his emphasis on the richness and messiness of human life, he might well have found the field of behavioral economics to be a bit thin, an abstraction from what can be learned from close observation of actual practices.

Of course, the challenge for close observers — and Hirschman was undoubtedly one — is to go beyond revealing anecdotes and interesting mechanisms to identify testable hypotheses. Can we test the idea of the Hiding Hand? We might imagine productive exchanges between contemporary economists and behavioral scientists, insistent on large sample sizes and hypothesis testing, and Hirschman, with his distrust of universal laws. For behavioral scientists, above all behavioral economists, the questions are obvious: What, exactly, is Hirschman's hypothesis, and how do we know that it is true? Is he suggesting some generalization of the planning fallacy and offering also a hypothesis about its productive effects? We might speculate that Hirschman would respond that he is not, in fact, offering a testable hypothesis, but instead a description of a mechanism, and a widespread phenomenon, that greatly illuminates how development projects actually operate.

As a storyteller and a social scientist, Hirschman is far too careful to suggest that whenever planners overestimate the likelihood of success, the Hiding Hand will come to the rescue. The Benevolent Hiding Hand, which is of course Hirschman's topic, has an evil twin, the Malevolent Hiding Hand, which also hides obstacles 
and difficulties, but in situations in which creativity does not emerge, or emerges too late, or cannot possibly save the day.

It would be extravagant to insist that it is generally or universally good for planners to underestimate difficulties on the ground that people will discover inventive and unanticipated ways to solve those difficulties. An uncharitable reading of this book would suggest that Hirschman has committed an identifiable error, which social scientists call "sampling on the dependent variable." Suppose, for example, that we wanted to understand what makes for a successful entrepreneur, and that we decided to find out by studying a set of successful entrepreneurs. Suppose we learned that the vast majority of them are exceedingly optimistic. From that finding, it would be a mistake to conclude that optimism is a necessary or sufficient condition for entrepreneurial success. There are a lot of failed entrepreneurs out there, and maybe most of them were exceedingly optimistic too. Maybe that trait, even if shared by the successful entrepreneurs, has no causal relationship to their success.

Hirschman identifies some striking instances of a Benevolent Hiding Hand, but his sample size is not large. There is little doubt that for countless unsuccessful development projects, the Hiding Hand did not work so well, or turned out to be malevolent, because the blindness at the initial stage is not countered by unanticipated creativity later on. True, and importantly, optimistic planners are sometimes rescued by such creativity, but much of the time, creativity is not triggered, and even if it is, it is not nearly enough to rescue their projects. We could easily imagine an impressive if somewhat downbeat book, perhaps with the same title as this one, that catalogs a set of failures, bred by a failure to foresee obstacles and challenges that confound planners of many sorts. Indeed, it is not necessary to exercise our imaginations. James Scott's wild and brilliant book, Seeing Like a State, is merely the best example.

Hirschman did not, of course, produce such a book, and I do not believe that writing it would have much interested him. While he liked human foibles, he was delighted not by blunders and failures, but by history's generous tricks, by serendipity and silver linings, and perhaps above all by "felicitous and surprising escapes from disaster." He was a realist, and no romantic, but he preferred happy endings. When the Benevolent Hiding Hand is at work, people's inability to foresee obstacles leads to actions that succeed because people have far more problem-solving ability than they anticipate. Perhaps that's not a law, or even a social science regularity. But it's a daily occurrence, and it deserves celebration, elaboration, and a name. 